\title{
Using hospital discharge data for determining neonatal morbidity and mortality: a validation study
}

\author{
Jane B Ford*1,2, Christine L Roberts ${ }^{1,2}$, Charles S Algert ${ }^{1,2}$, Jennifer R Bowen², \\ Barbara Bajuk ${ }^{3}$, David J Henderson-Smart ${ }^{3}$ for the NICUS group
}

\author{
Address: ${ }^{1}$ Perinatal Research Group, Kolling Institute of Medical Research, University of Sydney, New South Wales 2065, Australia., ${ }^{2}$ Royal North \\ Shore Hospital, St Leonards, New South Wales 2065, Australia. and ${ }^{3}$ Centre for Perinatal Health Services Research, University of Sydney, New \\ South Wales 2006, Australia. \\ Email: Jane B Ford* - jford@med.usyd.edu.au; Christine L Roberts - clroberts@med.usyd.edu.au; Charles S Algert - calgert@med.usyd.edu.au; \\ Jennifer R Bowen - jbowen@nsccahs.health.nsw.gov.au; Barbara Bajuk - barbara.bajuk@perinatal.usyd.edu.au; David J Henderson- \\ Smart - dhs@perinatal.usyd.edu.au \\ * Corresponding author
}

Published: 20 November 2007

BMC Health Services Research 2007, 7:188 doi:10.1 186/1472-6963-7-188

This article is available from: http://www.biomedcentral.com/I472-6963/7//88

(C) 2007 Ford et al; licensee BioMed Central Ltd.

This is an Open Access article distributed under the terms of the Creative Commons Attribution License (http://creativecommons.org/licenses/by/2.0), which permits unrestricted use, distribution, and reproduction in any medium, provided the original work is properly cited.

\begin{abstract}
Background: Despite widespread use of neonatal hospital discharge data, there are few published reports on the accuracy of population health data with neonatal diagnostic or procedure codes. The aim of this study was to assess the accuracy of using routinely collected hospital discharge data in identifying neonatal morbidity during the birth admission compared with data from a statewide audit of selected neonatal intensive care (NICU) admissions.

Methods: Validation study of population-based linked hospital discharge/birth data against neonatal intensive care audit data from New South Wales, Australia for 2,432 babies admitted to NICUs, 1994-1996. Sensitivity, specificity and positive predictive values (PPV) with exact binomial confidence intervals were calculated for 12 diagnoses and 6 procedures.

Results: Sensitivities ranged from $37.0 \%$ for drainage of an air leak to $97.7 \%$ for very low birthweight, specificities all exceeded $85 \%$ and PPVs ranged from $70.9 \%$ to $100 \%$. In-hospital mortality, low birthweight $(\leq 1500 \mathrm{~g})$, retinopathy of prematurity, respiratory distress syndrome, meconium aspiration, pneumonia, pulmonary hypertension, selected major anomalies, any mechanical ventilation (including CPAP), major surgery and surgery for patent ductus arteriosus or necrotizing enterocolitis were accurately identified with PPVs over $92 \%$. Transient tachypnea of the newborn and drainage of an air leak had the lowest PPVs, $70.9 \%$ and $83.6 \%$ respectively.

Conclusion: Although under-ascertained, routinely collected hospital discharge data had high PPVs for most validated items and would be suitable for risk factor analyses of neonatal morbidity.

Procedures tended to be more accurately recorded than diagnoses.
\end{abstract}

\section{Background}

Population health data provide a powerful tool for investigating health outcomes and assessing health interven- tions[1,2]. Hospital discharge data represent a potential source of population-based data on neonatal health outcomes and associated maternal characteristics and condi- 
tions. Despite widespread use of neonatal hospital discharge data [3-5], there are few published reports on the accuracy of population health data with neonatal diagnostic or therapeutic intervention codes[6]. Validation of neonatal outcomes in Australian hospital discharge data has been limited to diagnosis-related codes[7], although health interventions and procedures are generally better reported in population health data and may be better markers of morbidity [8-10]. Furthermore previous validation studies of neonatal outcomes have been random samples from the entire birth population, and have therefore included few high risk babies so the assessments of severe morbidity reporting has lacked precision $[7,11]$.

Regionalized maternity care, in which high risk mothers and/or infants are transferred to higher levels of care, aims to ensure all women and their babies get the care they require[12]. In Australia, the highest level of perinatal care is provided by perinatal centres which provide both tertiary obstetric care and neonatal intensive care. While there is currently a statewide New South Wales (NSW) audit of babies who are admitted to neonatal intensive care units (NICU) for selected reasons [13], there is no populationbased reporting on all babies admitted to NICU or who suffer a major morbidity.

Accurate population measures of neonatal morbidity would enable assessment of the quality of all levels of care[14]. Establishing the accuracy of morbidity reporting among high risk babies in population data (compared with available audit data) would allow us to maximise the usefulness of population health data in tracking changes in the high-risk neonatal population and facilitate further study on the effectiveness of regionalized maternity care using linked population data. Of particular interest is whether the babies identified as having a neonatal morbidity or procedure in the population data genuinely have a serious morbidity associated with their birth. This measure, the positive predictive value (PPV), is used to quantify the usefulness of routinely collected population health data[15]. Therefore the aim of this study was to assess the accuracy of the routinely collected hospital discharge data in identifying neonatal morbidity among high risk infants during the birth admission to hospital compared with a statewide audit (gold standard) of selected NICU admissions.

\section{Methods}

NSW is the most populous state in Australia with 6.3 million people and 86,000 births per annum, of which $<0.5 \%$ are planned home births $[13,16]$. The state has an area of $800,000 \mathrm{~km}^{2}$ and population densities range from 2,000 persons $/ \mathrm{km}^{2}$ in the coastal cities to $<0.1$ person/ $\mathrm{km}^{2}$ in the most remote areas[16].
Data for this study were obtained from three different datasets. The NSW Midwives Data Collection (MDC) is a legislated population-based surveillance system covering all births in NSW public and private hospitals $\geq 20$ weeks gestation or $\geq 400 \mathrm{~g}$ birthweight, as well as homebirths and includes data on maternal characteristics, pregnancy, labour, delivery and infant outcomes [13]. The NSW Admitted Patient Data Collection (APDC) is a census of all NSW inpatient hospital discharges, coded according to the 9th revision of the International Classification of Diseases, Ninth Revision, Clinical Modification (ICD9) with up to 11 diagnoses and 10 procedures coded per hospital stay during the study period[17]. Hospital coders use all available information in the medical record to code diagnoses and procedures. The Neonatal Intensive Care Units (NICUS) Data Collection is an audit of selected neonatal admissions to a NSW Neonatal Intensive Care Unit for one of the following NICUS registration criteria: gestational age less than 32 weeks, birthweight $\leq 1500$ gms, mechanical ventilation for 4 hours or more, continuous positive airways pressure (CPAP) for 4 hours or more, and/or major surgery (opening of a body cavity)[13]. NICUS includes neonatal diagnoses and procedures which were abstracted by 8 clinical nurse specialists with neonatal intensive care experience using standard data abstraction forms and definitions in each of 8 neonatal intensive care units during the study period[13]. Data are retrospectively abstracted from medical records and cover details of the first NICU admission, the hospital babies were transferred from and to, selected diagnoses and procedures that were performed during the first or subsequent NICU admissions, before discharge home. For example, if a baby is transferred from a perinatal centre NICU to a children's hospital for surgery, the surgical procedures are recorded in a single NICUS record. NICUS data were considered to be the 'gold standard' in this validation since it is abstracted by trained professionals located in each of the neonatal intensive care units.

\section{Record linkage}

For the years 1994-1996, NICUS records were linked to the APDC via MDC birth records. Direct linkage of NICUS and APDC records has not been undertaken, however NICUS and MDC records have previously been linked as have MDC-APDC records. The NSW Department of Health uses probabilistic record linkage which has been described elsewhere [18]. Only de-identified data were available to researchers.

When the datasets were limited to babies born in perinatal centres in NSW there were 68956 birth records eligible for linkage (of which 2927 potentially met the NICUS registration criteria) and 2690 NICUS records. Given that some babies will die before NICUS admission and others will be ventilated for less than four hours it is not surpris- 
ing that there were 237 additional birth records identified. After linkage there were 108 (3.7\%) records that partially linked (NICUS linked to a MDC record but the MDC did not link to an APDC record), and 150 (5.1\%) NICUS records that did not link to an MDC record, leaving 2432 linked records available for analysis.

\section{Diagnoses and procedures available for assessment of accuracy and reliability}

Diagnoses available for comparison on both NICUS and the APDC included: very low birthweight, death in hospital, intraventricular hemorrhage (IVH), retinopathy of prematurity (ROP), necrotizing enterocolitis (NEC) and selected major anomalies including anomalies of the dia- phragm, abdominal wall anomalies, spina bifida, tracheooesophageal fistula (TOF) stenosis or atresia, and tetralogy of fallot. We also assessed any brain hemorrhage, respiratory distress syndrome (RDS), transient tachypnea of the newborn (TTN), meconium aspiration, pneumonia and pulmonary hypertension (Table 1) although these variables are not collected in the same way on each data set (Table 2). NICUS data for some of these variables involved reporting of a primary diagnosis, and consequently not all diagnoses were necessarily recorded in these data. Procedures available for assessment included patent ductus arteriosus (PDA) surgery, NEC surgery, major surgery (using the NICUS definition of opening of a body cavity), drainage of an air leak, continuous positive

Table I: Accuracy of reporting in the NSW Inpatient Statistics Collection, New South Wales, Australia, $1994-1996$

\begin{tabular}{|c|c|c|c|c|c|c|c|}
\hline Description & $\begin{array}{r}\text { NICUS data } \\
\mathbf{N}\end{array}$ & $\begin{array}{r}\text { APDC data } \\
\mathbf{N}\end{array}$ & $\begin{array}{r}\text { Both data sets* } \\
\mathbf{N}\end{array}$ & $\begin{array}{c}\text { Sn \% } \\
(95 \% \mathrm{CI})\end{array}$ & $\begin{array}{c}\text { Sp \% } \\
(95 \% \mathrm{CI})\end{array}$ & $\begin{array}{l}\text { NPV \% } \\
(95 \% \mathrm{CI})\end{array}$ & $\begin{array}{c}\text { PPV \% } \\
(95 \% \mathrm{CI})\end{array}$ \\
\hline \multicolumn{8}{|l|}{ Diagnoses } \\
\hline $\begin{array}{l}\text { Death in birth } \\
\text { admission }\end{array}$ & 289 & 261 & 260 & $90.0(85.9-93.2)$ & $100(99.7-100)$ & $98.7(98.1-99.1)$ & $99.6(97.9-100)$ \\
\hline $\begin{array}{l}\text { Very low } \\
\text { birthweight } \\
400-1499 \mathrm{~g}\end{array}$ & 1,242 & 1,216 & 1213 & 97.7 (96.7-98.4) & 99.7 (99.2-99.9) & $97.6(96.5-98.4)$ & 99.8 (99.3-99.9) \\
\hline $\begin{array}{l}\text { Intra-ventricular } \\
\text { hemorrhage }\end{array}$ & 394 & 238 & 205 & $52.0(47.0-57.1)$ & 98.4 (97.7-98.9) & $91.4(90.1-92.5)$ & 86.1 (8I.I-90.3) \\
\hline $\begin{array}{l}\text { Any brain } \\
\text { hemorrhage } \neq\end{array}$ & 400 & 281 & 251 & $62.8(57.8-67.5)$ & 98.4 (97.7-98.9) & $92.4(91.1-93.5)$ & $89.3(85.1-92.7)$ \\
\hline $\begin{array}{l}\text { Retinopathy of } \\
\text { prematurity }\end{array}$ & 273 & 169 & 157 & $57.5(51.4-63.4)$ & 99.4 (99.0-99.7) & 94.9 (93.9-95.7) & $92.9(87.9-96.3)$ \\
\hline $\begin{array}{l}\text { Respiratory distress } \\
\text { syndrome }\end{array}$ & 1205 & 1022 & 991 & $82.2(80.0-84.4)$ & $92.4(89.4-94.8)$ & $63.9(59.8-67.7)$ & 97.0 (95.7-97.9) \\
\hline $\begin{array}{l}\text { Transient } \\
\text { tachypneaf }\end{array}$ & 347 & 206 & 146 & $42.1(36.8-47.5)$ & $85.3(81.5-88.6)$ & $63.5(59.3-67.5)$ & $70.9(64.2-77.0)$ \\
\hline $\begin{array}{l}\text { Meconium } \\
\text { aspiration } \ddagger\end{array}$ & 56 & 40 & 38 & $67.9(54.0-79.7)$ & 99.5 (98.2-99.9) & $95.8(93.4-97.5)$ & $95.0(83.1-99.4)$ \\
\hline Pneumonia & 29 & 15 & 14 & $48.3(29.4-67.5)$ & $99.8(98.6-100)$ & $96.5(94.2-98.0)$ & 93.3 (68.1-99.8) \\
\hline $\begin{array}{l}\text { Pulmonary } \\
\text { hypertension } \neq\end{array}$ & 53 & 34 & 34 & 64.2 (49.8-79.9) & $100(99.1-100)$ & $95.6(93.2-97.3)$ & $100(89.7-100)$ \\
\hline $\begin{array}{l}\text { Necrotizing } \\
\text { enterocolitis }\end{array}$ & 76 & 55 & 47 & $61.8(50.0-72.8)$ & 99.7 (99.3-99.9) & $98.8(98.3-99.2)$ & 85.5 (73.3-93.5) \\
\hline $\begin{array}{l}\text { Selected major } \\
\text { anomaliest }\end{array}$ & 41 & 42 & 39 & 95.1 (83.5-99.4) & $99.9(99.6-100)$ & $99.9(99.7-100)$ & $92.9(80.5-98.5)$ \\
\hline \multicolumn{8}{|l|}{ Procedures } \\
\hline $\begin{array}{l}\text { Any mechanical } \\
\text { ventilation } \\
\text { (including CPAP) }\end{array}$ & 2,023 & 1,552 & 1540 & 76.1 (74.2-78.0) & 97.1 (94.9-98.5) & $45.1(41.8-48.5)$ & 99.2 (98.7-99.6) \\
\hline $\begin{array}{l}\text { Cont. positive } \\
\text { airways pressure }\end{array}$ & 1055 & 785 & 691 & $65.5(62.5-68.4)$ & 93.2 (91.7-94.4) & 77.9 (75.8-79.9) & $88.0(85.5-90.2)$ \\
\hline Drainage of air leak & 135 & 60 & 50 & $37.0(28.9-45.8)$ & $99.6(99.2-99.8)$ & $96.4(95.6-97.1)$ & 83.3 (7I.5-9I.7) \\
\hline $\begin{array}{l}\text { Patent ductus } \\
\text { arteriosus surgery }\end{array}$ & 19 & 18 & 18 & 94.7 (74.0-99.9) & $100(99.8-100)$ & $100(99.8-100)$ & $100(81.5-100)$ \\
\hline $\begin{array}{l}\text { Necrotizing } \\
\text { enterocolitis } \\
\text { surgery }\end{array}$ & 17 & 14 & 14 & $82.4(56.6-96.2)$ & $100(99.8-100)$ & $99.9(99.6-100)$ & $100(76.8-100)$ \\
\hline Major surgery & 77 & 74 & 70 & $90.9(82.2-96.3)$ & $99.8(99.6-100)$ & 99.7 (99.4-99.9) & 94.6 (86.7-98.5) \\
\hline
\end{tabular}

Sn = Sensitivity, Sp = Specificity; $* N=2,432$

†Selected major anomalies included diaphragm anomalies, abdominal wall anomalies, spina bifida, tracheo-esophageal fistula and tetralogy of fallot. $\ddagger$ These diagnoses may be under-recorded in the NICUS data since only a primary diagnosis could be recorded (see Table 2) 
Table 2: Comparison of NICUS variable codes and ICD9 codes available in the Admitted Patient Data Collection, New South Wales, Australia, 1994-1996

\begin{tabular}{|c|c|c|}
\hline & NICUS variable codes & Available ICD9 codes \\
\hline \multicolumn{3}{|l|}{ Diagnoses } \\
\hline $\begin{array}{l}\text { Intraventricular hemorrhage (IVH) } \\
\text { and other brain hemorrhages }\end{array}$ & $\begin{array}{l}\text { IVH was coded as YES (grades I-4) or NO (none/not examined) } \\
\text { A single head ultrasound (HUS) abnormality can be recorded and } \\
\text { coded: } \\
\text { 0:None; I:Cerebral oedema; } 2: \text { Subarachnoid hemorrhage; } \\
\text { 3:Periventricular echogenicity; } 4 \text { :Cerebellar hemorrhage; } \\
\text { 5:Subdural hemorrhage; } 6: \text { Extradural hemorrhage; } 7: \text { Other; } 8 \\
\text { Not examined. } \\
\text { Any brain hemorrhage was coded YES where IVH = YES or HUS } \\
\text { in }(2,4,5,6) \text { and NO where HUS abnormality of 'none' or 'not } \\
\text { examined'. }\end{array}$ & $\begin{array}{l}\text { 772.I Neonatal IVH } \\
\text { 772.2 Neonatal subarachnoid hemorrhage } \\
\text { 767.0 Subdural and cerebral hemorrhages } \\
\text { 772.I, } 772.2 \text { or } 767.0 \text { any brain } \\
\text { hemorrhage }\end{array}$ \\
\hline \multirow[t]{3}{*}{ Respiratory diagnoses } & $\begin{array}{l}\text { A single 'primary respiratory diagnosis' can be recorded and } \\
\text { coded: } \\
\text { 0:None; I:Transient tachypnea of the newborn (TTN); } \\
\text { 2:Respiratory distress syndrome (RDS); 3:Meconium aspiration; } \\
\text { 4:Immature lung; 5:Apnea; 6:Congenital anomaly; 7: Pulmonary } \\
\text { hypertension; 8:Pneumonia; 9:Perinatal surgery; 10:Other; or } \\
\text { II:Unknown }\end{array}$ & $\begin{array}{l}\text { 769 Respiratory distress syndrome } \\
\text { (neonatal) } \\
\text { 770.6 Transient tachypnea of the newborn } \\
\text { 770.1 Meconium aspiration syndrome } \\
\text { 770.0 Congenital pneumonia } \\
\text { 480-486 Pneumonia } \\
\text { 416.0 Pulmonary hypertension }\end{array}$ \\
\hline & $\begin{array}{l}\text { A single 'main indication for initial ventilation" can also be } \\
\text { recorded and coded 1-7 as above or; 8:Infection (any site); } \\
\text { 9:Asphyxia; 10: Cardiac disorder; II:Post-surgery; 12:Other }\end{array}$ & \\
\hline & $\begin{array}{l}\text { Any diagnosis of transient tachypnea, respiratory distress } \\
\text { syndrome, meconium aspiration, pulmonary hypertension or } \\
\text { pneumonia was coded YES and 'primary respiratory diagnosis of } \\
\text { 'none' coded NO }\end{array}$ & \\
\hline Retinopathy of prematurity (ROP) & $\begin{array}{l}\text { ROP was coded as YES (grades } \mathrm{I}-4 \text { or treatment for ROP) or } \\
\text { NO (none/not examined) }\end{array}$ & $\begin{array}{l}\text { 362.2I Retrolental fibroplasia } \\
\text { 362.10 Retinopathy unspecified } \\
\text { 14.2 Destruction of chorioretinal lesion } \\
\text { 36.21, } 362.10 \text { or I4.2 coded as ROP }\end{array}$ \\
\hline Necrotizing enterocolitis (NEC) & $\begin{array}{l}\text { NEC coded as YES (clinically diagnosed or proven radiologically/ } \\
\text { at surgery) or NO (None) }\end{array}$ & $\begin{array}{l}777.5 \text { Necrotizing enterocolitis in } \\
\text { newborn }\end{array}$ \\
\hline Selected major anomalies & $\begin{array}{l}\text { Recorded using ICD9 diagnosis codes for any of the following: } \\
\text { anomalies of diaphragm, anomalies of abdominal wall, spina bifida, } \\
\text { tracheo-oesophageal fistula (TOF), oesophageal atresia and } \\
\text { stenosis and tetralogy of fallot (see next column for ICD codes) }\end{array}$ & $\begin{array}{l}\text { 756.6 Diaphragm anomalies } \\
\text { 756.7 Abdominal wall anomalies } \\
\text { 74I Spina bifida } \\
\text { 750.3 TOF, oesophageal atresia and } \\
\text { stenosis } \\
\text { 745.2 Tetralogy of fallot }\end{array}$ \\
\hline \multicolumn{3}{|l|}{ Procedures } \\
\hline $\begin{array}{l}\text { Continuous positive airway } \\
\text { pressure (CPAP) }\end{array}$ & $\begin{array}{l}\text { Recorded using } 4 \text { variables indicating number of days of } \\
\text { endotracheal tube CPAP, nasopharyngeal CPAP, continuous } \\
\text { nasal CPAP and intermittent nasal CPAP: I or more days of any } \\
\text { of these recorded as YES, } 0 \text { days recorded as NO }\end{array}$ & $\begin{array}{l}93.90 \text { Continuous positive airway pressure } \\
\text { (CPAP) }\end{array}$ \\
\hline $\begin{array}{l}\text { Mechanical ventilation (including } \\
\text { CPAP) }\end{array}$ & Mechanical ventilation or CPAP, YES or otherwise NO & $\begin{array}{l}\text { 93.90 Continuous positive airway pressure } \\
\text { (CPAP) } \\
93.91 \text { Intermittent positive airway } \\
\text { pressure breathing } \\
96.7 \text { Continuous mechanical ventilation } \\
93.90,93.91 \text {, or } 96.7 \text { for any mechanical } \\
\text { ventilation }\end{array}$ \\
\hline Drainage of air leak & Recorded as air leak requiring drainage YES or NO & $\begin{array}{l}34.04 \text { Insertion of intercostal catheter for } \\
\text { drainage }\end{array}$ \\
\hline $\begin{array}{l}\text { Surgery for patent ductus } \\
\text { arteriosus (PDA) }\end{array}$ & PDA surgery coded as YES or NO & 38.85 Ligation of PDA \\
\hline $\begin{array}{l}\text { Surgery for necrotizing } \\
\text { enterocolitis (NEC) }\end{array}$ & NEC surgery coded as YES or NO & $\begin{array}{l}777.5 \text { Necrotizing enterocolitis in } \\
\text { newborn } \\
45.6-46.5 \text { Operations on the small or large } \\
\text { intestine } \\
43.19 \text { Other gastrostomy } \\
54.11,54.19 \text { Laparotomy } \\
54.59 \text { Lysis of peritoneal adhesions } \\
77.5 \text { and } 45.6-46.5,43.19,54.11,54.19 \text {, or } \\
54.59 \text { for NEC surgery }\end{array}$ \\
\hline
\end{tabular}


airways pressure (CPAP) and any mechanical ventilation (including CPAP). If no diagnosis or procedure was recorded it was presumed to be absent. Gestational age in weeks was available on the MDC but not routinely reported on APDC data. See Appendix 1 for a comparison of the collection and format of the dichotomous variables compared on both datasets.

\section{Analysis}

Linked MDC-APDC-NICUS records of babies born in perinatal centres were compared with non-linking birth records that fulfilled the NICUS registration criteria using the chi-square test and a significance level of 0.05. MDC gestational age was used for assessing of NICUS criteria. Among the linked records the reporting of diagnoses and procedures on the APDC was assessed by determining the sensitivity, specificity, positive predictive values (PPV) and negative predictive values (NPV) with exact binomial confidence intervals[19], using the NICUS as the 'gold standard'. Sensitivity was the percentage of babies with a diagnosis/procedure identified in NICUS for whom the same diagnosis/procedure was reported on the hospital discharge data, therefore denoting the completeness of identification by hospital discharge data. Specificity was the percentage of babies without a diagnosis/procedure on NICUS who were correctly reported as not having it in the hospital discharge data. Positive predictive value was the percentage of babies' reports in the hospital discharge data with the same diagnosis/procedure reported in the NICUS audit. Negative predictive value was the percentage of babies reported as not having a diagnosis/procedure in hospital discharge data for whom a NICUS report was also absent. The PPV and NPV are measures of the accuracy of the hospital data. Positive likelihood ratios were also reported as a measure of accuracy which takes into account the prevalence of a condition/procedure. Likelihood ratios of above 10 are considered to provide strong evidence to rule in diagnoses in most circumstances [20], with the larger likelihood ratios indicating greater likelihood of correct reporting if the diagnosis/procedure is present in the hospital discharge data. In using population-based data for risk factor analyses it is important that identified cases are true cases (high PPV). Analyses were carried out using SAS v9.1. The study protocol was approved by the Sydney South West Area Health Service Ethics Review Committee.

\section{Results}

During 1994-1996, there were 2927 babies born in perinatal centres in NSW with linked MDC-APDC birth records that potentially met the NICUS registration criteria and 2432 (83\%) that actually linked to a NICUS record. Compared with records that linked to NICUS, those that did not link were significantly $(\mathrm{p}<0.0001)$ more likely to include babies who: died on the day of birth ( $11 \%$ vs $2 \%)$ were born at $\geq 32$ weeks gestation ( $26 \%$ vs $11 \%)$, birthweight $\geq 1500 \mathrm{~g}(38 \%$ vs $25 \%)$ or transferred to another perinatal centre ( $36 \%$ vs $0.2 \%$ ).

Of the 2432 babies who had birth records that linked to a NICUS record, 1591 (65.4\%) were registered in NICUS because they were $\leq 1500 \mathrm{~g}$ or $<32$ weeks, $831(34.2 \%)$ for any mechanical ventilation (including CPAP) and 10 $(0.4 \%)$ for major surgery. Table 1 summarises the sensitivity, specificity, and PPV for the morbidities and procedures that could be compared in NICUS and the APDC.

There was a wide range of sensitivities for the reporting of neonatal morbidities, ranging from $42 \%$ for TTN to $98 \%$ for very low birthweight (Table 1). Of the 12 morbidities compared, all but one (TTN) had PPVs over $80 \%$ and eight were over $90 \%$ including death in hospital, very low birthweight, RDS, meconium aspiration, pneumonia, pulmonary hypertension, ROP and the selected major anomalies (Table 1).

The selected congenital anomalies were well identified. There was perfect agreement between the datasets for TOF $(n=5)$ and spina bifida $(n=5)$, with high PPVs for other anomalies ranging from $83 \%$ for tetralogy of fallot $(n=5)$ to $87 \%$ for abdominal wall anomalies $(n=14)$ and $94 \%$ for anomalies of the diaphragm $(n=16)$.

Four out of the six procedures validated had PPVs of 95\% or above. Although ascertainment of any mechanical ventilation (including CPAP) was only $76 \%$, the PPV was extremely high at $99 \%$ indicating false positives rarely occur (Table 1). In contrast, CPAP as a specific procedure was less accurately recorded with a PPV of $88 \%$ and a sensitivity of $66 \%$. However, an additional 165 cases of CPAP were identified in the hospital data as having mechanical ventilation of some kind, so that its ascertainment rose to $81 \%$ within this broader category. Drainage of an air leak had a low ascertainment rate. The identification of major and specific surgeries was very accurate with PPVs of $95 \%$ or more.

Positive likelihood ratios were above 10 for all diagnoses except transient tachypnea and all procedures except CPAP. The range of values above 10 were from 10.8 for respiratory distress syndrome to 951 for selected major anomalies.

\section{Discussion}

In general, the findings of this validation study are consistent with other validation studies that compare routinely collected population health data with medical records $[15,21,22]$. Diagnoses and procedures tend to be under-ascertained in population health data[8], but the majority of the cases that are identified are true cases with 
PPVs over $80 \%$. Procedures are generally more accurately reported than diagnoses $[9,11,22]$, with only two procedures with a PPV below 95\% in this study.

It is important to note that validation of data from a high risk population presents particular challenges. Preterm and very low birthweight babies are likely to have multiple diagnoses and procedures recorded. While hospital discharge data are structured to record multiple diagnoses and procedures, audit data in some cases involves assessments of primary diagnoses, (for example, primary respiratory diagnosis) and consequently not all diagnoses are necessarily recorded for 6 of the 18 items validated (see Table 1). In addition, the widespread use of mechanical ventilation and monitoring in the NICU population may result in brief interventions ( $<4$ hours) not being recorded in audit data (in an attempt to only include true respiratory pathology) whereas administrative requirements dictate the need for recording of all interventions in the hospital discharge data.

Previous research has shown that demographic variables such as infant sex, birthweight, and in Australia gestational age, are well recorded[11,23]. This is the first time birthweight (as identified in the hospital discharge data) has been validated, with encouraging results. Although restricted to validation of very low birthweight, a PPV of over $99 \%$ indicates that this variable can be used to identify high risk babies in the hospital discharge data. As the NICUS registration criteria (birthweight $\leq 1500 \mathrm{~g}$, mechanical ventilation and major surgery) were identified with a high probability (PPVs $>94 \%$ ) in the APDC and gestational age is well reported in the MDC[11], these babies can be readily identified from the linked birth data.

Some diagnoses, such as TTN and brain hemorrhages, had lower PPVs. This is likely to be related to reporting differences between the datasets. NICUS may under-enumerate some conditions when it allows only a single diagnosis, such as primary respiratory diagnosis or head ultrasound abnormality; additional related diagnoses are not recorded. For example a baby may have both meconium aspiration and pulmonary hypertension or a subarachnoid hemorrhage and cerebral oedema, but only one of these could be coded. In contrast the APDC could capture all diagnoses and therefore may include true cases that NICUS does not. Furthermore, TTN may be difficult to diagnose and may resolve with minimal intervention, and as such, may be less likely to be reported. Medical record coding is better where a major intervention or procedure occurs [9].

Other diagnoses could not be compared in the two datasets because there were no specific ICD9 codes (eg. immature lung, periventricular echogenicity and cerebellar hemorrhage) or there were only very general, non-specific codes that included other diagnoses. For example apnea is included in the ICD9 code ' 770.8 Other respiratory problems at birth' which also includes cyanotic attacks, respiratory distress and respiratory failure not otherwise specified.

Despite differences between the datasets in the recording of any mechanical ventilation, the PPV was $99 \%$. One of the NICUS registration criteria is mechanical ventilation for $\geq 4$ hours but it is not possible to impose this duration limit on APDC data. The APDC records any non-operating theatre mechanical ventilation so it is entirely possible that infants reported as receiving mechanical ventilation in the APDC, but not in the NICUS data, did receive ventilation but of less than four hours duration. The more specific code of CPAP was less accurately reported than the codes that capture any mechanical ventilation which included CPAP. This is consistent with other studies involving hospital data which have shown that broader categories have greater validity than very specific categories[7,24].

The availability of record linkage only for the birth admission limited our ability to validate the reporting of surgical procedures. Most neonatal surgery is performed at children's hospitals in which there are no births[25]. Therefore there are, and rightly should be, few cases of surgical procedures reported in this study population. Nevertheless, the surgical procedures that could be assessed were identified with an extremely high level of accuracy especially for the highly specific procedure of ligation of a PDA.

It is unclear why air leak requiring drainage had a markedly lower sensitivity (38\%) than other procedures, although most of the cases identified in the APDC (83\%) were true cases according to NICUS. Major surgical procedures conducted in an operating theatre may be better ascertained in hospital discharge records than procedures that were probably undertaken in the NICU as a component of neonatal intensive care, such as insertion of a chest drain or mechanical ventilation.

Potential criticisms of the study include variations in recording of diagnoses/procedures between the two datasets, possible under-ascertainment of selected NICUS variables and the use of data that are more than ten years old. Linkage of MDC-APDC-NICUS data was only conducted for the three year period covered by this study and is unlikely to be extended to cover more recent years. There have been changes in the risk profile of women giving birth[13] (eg higher proportions of pregnancies with a history of cesarean delivery, advancing maternal age) potentially resulting in an increased proportion of complicated 
births since 1996. At the same time there has been increased survival of preterm infants born at earlier gestational ages [26]. However, these trends have probably affected the numbers and proportions of babies with particular diagnoses (eg. retinopathy of prematurity), but are unlikely to have negatively affected the recording of these diagnoses. If anything such potentially increased incidence would be likely to improve reporting [27].

\section{Implications for population-based analyses}

Hospital discharge data are an important resource for health surveillance, informing health service provision and risk factor analyses. While under-ascertainment affects the reporting of the prevalence of diagnoses and procedures and thus will result in under-reporting of baby outcomes, it may have little impact on the analysis of risk factors because the number of non-reported cases (false negatives) is very small relative to the number of noncases (true negatives) in population data[28]. For example, if only $62 \%$ of NEC diagnoses are identified in a population of 100,000 live births with an expected incidence of 110 babies with NEC [29], the 42 missed cases would not impact a risk factor analysis if they were included in the 99,800 babies who did not have NEC. Consequently moderately low sensitivities for severe morbidity reporting of diagnoses such as NEC and ROP does not preclude their use in risk factor analyses in population data. This assumes, however, that there is non-differential misclassification of cases and non-cases with respect to determinants and confounders, and in terms of severity. These are important issues for consideration given that hospital discharge data appears to capture more severe cases $[30,31]$ and may over-estimate associations with outcomes [30].

Given the high-risk study population in this study and the impact that prevalence has on PPVs, the predictive values for common diagnoses/procedures observed in this study, such as very low birthweight, respiratory distress syndrome and mechanical ventilation, will not necessarily be transferable to other studies. In a low-risk population we would be more sure that no such recorded diagnosis/procedure indicated true absence, and less sure that a positive result really indicated a condition/procedure was present [32]. Nevertheless, likelihood ratios indicate these items will be useful in wider hospital discharge data.

As expected, more records in the linked birth admissions at perinatal centres fulfilled the NICUS registration criteria than linked with a NICUS record. This is because the perinatal centre population data includes labour ward deaths[33], babies transferred to other NICUs and larger or more mature babies who were ventilated for $<4$ hours. This is a reminder that NICUS is an audit of selected NICU admissions and cannot provide a population measure of neonatal morbidity and mortality. While differential recording accuracy may occur between low-risk and highrisk populations[34], we would expect recording to be consistent within the high-risk population. Therefore, we would expect these findings would be generalizable to other high risk babies not included in our study (eg. babies transferred to another NICU, term babies with meconium aspiration). Reassuringly, our results are comparable with an audit of a random sample of 500 babies conducted in 1999-2000 which, though based on small numbers of cases, similarly showed some under-reporting but high PPVs for intraventricular hemorrhage $(\mathrm{n}=4)$, respiratory distress syndrome $(\mathrm{n}=14)$, meconium aspiration $(n=4)$ and congenital anomalies $(n=49)$ among the general neonatal population[7].

\section{Conclusion}

Assuming that the accuracy of the neonatal morbidity reporting is generalizable to other high risk babies in the hospital discharge data (not included in our study), a composite measure of neonatal morbidity (based on identification from a prescribed list of validated morbidities) could be developed and applied to all births and not just those fulfilling the NICUS registration criteria. However, to capture all neonatal morbidity would require birth admission data to be linked to subsequent admissions including those following transfer to a perinatal centre or children's hospital[35].

\section{Competing interests}

The author(s) declare that they have no competing interests.

\section{Authors' contributions}

JF and CR conceived and designed the study and undertook analysis and interpretation, CA participated in analysis and interpretation, JB and DHS participated in interpretation and BB acquired and linked data and participated in interpretation. All authors read and approved the final manuscript.

\section{Acknowledgements}

We wish to acknowledge the efforts of the hospital staff/NICUS audit officers who collect the data, and NSW Department of Health staff for their role in the data linkage. Jane Ford is supported by the Health Research and Outcomes Network, a National Health and Medical Research Council (NHMRC) Capacity Building Grant in Population Health Research. Christine Roberts is supported by a NHMRC Research Fellowship. These funding sources played no role in conduct of this study or writing of this paper.

\section{References}

I. Stanley FJ, Croft ML, Gibbins J, Read AW: A population database for maternal and child health research in Western Australia using record linkage. Paediatric \& perinatal epidemiology 1994, 8:433-447.

2. Roos LL, Sharp SM, Cohen MH: Comparing clinical information with claims data: some similarities and differences. Clinical Epidemiology 1991, 44:881-888. 
3. Durbin DR, Giardino AP, Shaw KN, Harris MC, Silber JH: The effect of insurance status on likelihood of neonatal interhospital transfer. Pediatrics 1997, 100:E8.

4. Edmonson MB, Stoddard JJ, Owens LM: Early hospital discharge of newborn infants was not associated with feeding related hospital readmission during the first 28 days of life. JAMA 1998, 278:299-303.

5. Morbidity and Mortality Weekly Report: Hospital stays, hospitals charges and in-hospital deaths among infants with selected birth defects - United States, 2003. MMWR 2007, 56:25-29.

6. Gould JB, Danielsen B, Korst LM, Phibbs R, Chance K, Main E, Wirtschafter DD, Stevenson DK: Cesarean delivery rates and neonatal morbidity in a low-risk population. Obstetrics \& Gynecology 2004, 104:11-19.

7. Taylor L, Travis S, Pym M, Olive E, Henderson-Smart D: How useful are hospital morbidity data for monitoring conditions occurring in the perinatal period? Australian and New Zealand Journal of Obstetrics and Gynaecology 2005, 45:36-4I.

8. Yasmeen S, Romano PS, Schembri ME, Keyzer JM, Gilbert WM: Accuracy of obstetric diagnoses and procedures in hospital discharge data. Am J Obstet Gynecol 2006, I 94:992-I00I.

9. Fisher ES, Whaley FS, Krushat WM, Malenka DJ, Fleming C, Baron JA, Hsia DC: The accuracy of medicare's hospital claims data: progress has been made, but problems remain. American Journal of Public Health 1992, 82:243-248.

10. Schwartz RM, Gagnon DE, Muri JH, Zhao QR, Kellogg R: Administrative data for quality improvement. Pediatrics 1999, 103:291-301.

II. NSW Health Department: Validation study: NSW Midwives Data Collection I 998. In New South Wales Mothers and Babies 1998 Volume 9. , NSW Public Health Bulletin, State Publication no. (EPI) 000029; 2000:97-99.

12. Cifuentes J, Bronstein J, Phibbs CS, Phibbs RH, Schmitt SK, Carlo WA: Mortality in low birth weight infants according to level of neonatal care at hospital of birth. Pediatrics 2002, I 09:745-75I.

13. Centre for Epidemiology and Research - NSW Department of Health: New South Wales Mothers and Babies 2004. NSW Public Health Bulletin 2005, 16:S-4.

14. Jones L, LoGerfo JP, Shy K, Connell FA, Holt VL, Parrish KM, McCandless K: StORQS: Washington's statewide obstetrical review and quality system: overview and provider evaluation. Qrb Quarterly Review Bulletin 1993, 19:1 10-1 I8.

15. Lydon-Rochelle MT, Holt VL, Nelson JC, Cardenas V, Gardella C Easterling TR, Callaghan WM: Accuracy of reporting materna in-hospital diagnoses and intrapartum procedures in Washington State linked birth records. Paediatr Perinat Epidemiol 2005, 19:460-47|

16. Australian Bureau of Statistics: 200I Census of Population and Housing, Australia in Profile. [http://www.abs.gov.au/AUS STATS/abs@.nsf/DetailsPage/2032.02001? OpenDocument].

17. NSW Health Department: Inpatient Statistics Collection Instruction Manual. [http://hoist.health.nsw.gov.au/hoist/dataset/ isc/iscdoc.htm].

18. Ford JB, Roberts CL, Taylor LK: Characteristics of unmatched maternal and baby records in linked birth records and hospital discharge data. Paediatric \& perinatal epidemiology 2006 20:329-337.

19. Cha S, Bagniewski S: Calculate sensitivity and specificity. 2005 [http://mayoresearch.mayo.edu/mayo/research/biostat/upload/ senspe.sas]. , Mayo Clinic College of Medicine

20. Deeks J], Altman DG: Diagnostic tests 4: likelihood ratios. $B M$ 2004, 329: 168-169.

21. Lydon-Rochelle MT, Holt VL, Cardenas V, Nelson JC, Easterling TR, Gardella C, Callaghan WM: The reporting of pre-existing maternal medical conditions and complications of pregnancy on birth certificates and in hospital discharge data. American Journal of Obstetrics and Gynecology 2005, 193: 125-134.

22. Roos LL, Soodeen R, Jebamani L: An information-rich environment: linked-record systems and data quality in Canada. Proceedings of Statistics Canada Symposium 2001.

23. Wen SW, Liu S, Marcoux S, Fowler D: Uses and limitations of routine hospital admission/separation records for perinatal surveillance. Chronic Diseases in Canada 1997, I8:113-119.

24. Gould JB: Vital records for quality improvement. Pediatrics 1999, 103:278-290.
25. Badawi N, Adelson P, Roberts CL, Spence K, Laing S, Cass D: Neonatal surgery in New South Wales - what is performed where? Journal of Pediatric Surgery 2003, 38:1025-1031.

26. Horbar JD, Badger GJ, Carpenter JH, Fanaroff AA, Kilpatrick S, LaCorte M, Phibbs R, Soll RF: Trends in mortality and morbidity for very low birth weight infants, 1991-1999. Pediatrics 2002 I l 0:|43-151.

27. Dobie SA, Baldwin LM, Rosenblatt RA, Fordyce MA, Andrilla CHA, Hart LG: How well do birth certificates describe the pregnancies they report? The Washington State experience with low-risk pregnancies. Maternal and Child Health Journal I998, 2:145-154.

28. Roberts CL, Algert CS, Ford JB: Linked population health data: methods for dealing with discrepant records. BMC Health Services Research 2007, 7:12.

29. Holman RC, Stoll BJ, Curns AT, Yorita KL, Steiner C, Schonberger LB: Necrotising enterocolitis hospitalisations among neonates in the United States. Paediatr Perinat Epidemiol 2006, 20:498-506.

30. Roberts CL, Algert CS, Bell JC, Cameron CA, JM. M: Does severity influence reporting of conditions in administrative data?: ; Boston, USA. ; 2007.

31. Roberts CL, Bell JC, Ford JB, Hadfield R, Algert CS, Morris JM: The accuracy of reporting of the hypertensive disorders of pregnancy in population health data. Hypertension in Pregnancy in press.

32. Altman DG, Bland JM: Diagnostic tests 2: Predictive values. $B M$ 1994, 309:102.

33. Sutton L, Bajuk B, NSW Neonatal Intensive Care Unit Study Group: Population-based study of infants born at less than 28 weeks' gestation in New South Wales, Australia, 1992-3. Paediatr Perinat Epidemiol 1999, I 3:288-301.

34. Reichman NE, Hade EM: Validation of birth certificate data: a study of women in New Jersey's Healthstart program. Annals of epidemiology 200I, I I:I86-193.

35. Tomashek KM, Crouse CJ, lyasu S, Johnson CH, Flowers LM: A comparison of morbidity rates attributable to conditions originating in the perinatal period among newborns discharged from United States hospitals, 1989-90 and 1999-2000. Paediatr Perinat Epidemiol 2006, 20:24-34.

\section{Pre-publication history}

The pre-publication history for this paper can be accessed here:

http://www.biomedcentral.com/1472-6963/7/188/pre pub

Publish with Biomed Central and every scientist can read your work free of charge

"BioMed Central will be the most significant development for disseminating the results of biomedical research in our lifetime. "

Sir Paul Nurse, Cancer Research UK

Your research papers will be:

- available free of charge to the entire biomedical community

- peer reviewed and published immediately upon acceptance

- cited in PubMed and archived on PubMed Central

- yours - you keep the copyright
BioMedcentral 